\title{
IDEAS REGARDING THE MODELING OF THE BEHAVIOR OF THE SECTIONS HAVING A DISTINCT SHEAR CENTER
}

\author{
OANTA, E[mil]; PANAIT, C[ornel]; SABAU, A[drian]; \\ BARHALESCU, M[ihaela] L[uminita] \& AXINTE, T[iberiu]
}

\begin{abstract}
One of the measures frequently undertaken to minimize the cost of a structure is to use pre-engineered members, such as I-shaped members. The designer must take into consideration the behavior of such pre-engineered beams, being aware about the applied elasticity phenomena which might impose additional conditions regarding the numerical model. The paper presents some interesting aspects regarding the shear center issue, which may be applied in the concept and the design of the structures. Beside the theoretical aspects, there is presented a comparative study of two finite element models. Some practical conclusions are drawn,together with the identification of a new direction of study regarding the automatic calculus of the structures.
\end{abstract}

Keywords:Shear center, applied elasticity, appropriate finite element selection, practical solutions

\section{INTRODUCTION}

The cost minimization of the products is a basic objective for all the engineering team involved in concept, design, testing, manufacturing and maintenance. If the final product is the design of a structure, several aspects should be considered. The most popular design instrument nowadays is the computer and many CAD / CAE / CAM integrated applications offer many facilities which could not be foreseen a few years ago. Other solutions are given by the original software applications which use the modern information technologies and the according algorithms in order to create hybrid models which include advanced analytical aspects, [2], [3], [4], and [5]. Beside these facilities offered by the integrated CAD / CAE / CAM applications, the structural analyst is not replaced by these new intelligent applications, but empowered with new instruments of investigation. Accordingly, the analyst must possess a higher degree of knowledge regarding the theoretical aspects, the effective use of the software instruments and the practical solutions to be designed.

As an example that theory and modern instruments (such as FEM) must complete each other, we do consider the shear center issue problem.

\section{THEORETICAL BACKGROUND}

Some of the notions employed to compute the stresses in applied elasticity may be defined by taking into account geometrical aspects (like the centroid, area, second moment of area, aso) or combined, geometrical and mechanical aspects (such as the shear center, the neutral axis, aso).
The shear center is important because the twisting effect of the beams under transverse forces is less known. According to the technical literature, [1], the shear center is defined as the "point on a line parallel to the axis of a beam through which any transverse force must be applied to avoid twisting of the section. A beam section will rotate when the resultant of the internal shearing forces is not collinear with the externally applied force. The shear center may be determined by locating the line of action of the resultant of the internal shear forces." The shear center is also designated as "flexural center" and it should not be wrongfully mixed-up with the "center of twist"that is the point about which the section rotates when subjected to torsion.If the beam is subjected to pure torsion, then the center of twist is the same with the shear center. The shear center should also not be confused with the elastic center which is that point of a beam in the plane of the section lying midway between the flexural center and the center of twist in that section. If the cross section is homogeneous and symmetrical in both vertical and horizontal directions, then shear center, center of twist and elastic center are all located in the beam centroid.

The calculus of the position of the shear center takes into consideration the tangential stresses and uses the equilibrium condition between the torque produced by the tangential stresses and the torque produced by a virtual (external) force. For a random shape of the crosssection, the position of the shear center may be computed using the general expression:

$$
Y_{C}=-\frac{1}{I_{Y}} \cdot \int_{0}^{S_{1}}\left[r_{t} \cdot \int_{0}^{s}(z \cdot t) \cdot d s\right] \cdot d s
$$

Let us consider the model of a $\mathrm{C}$-shape beam (channel) presented in figure 1. The horizontal rectangles are the flanges of the section and the vertical, central rectangle is the web of the section. We do consider that the web and the flanges have the same thickness, denotedby $\delta$. The vertical distance between the midpoints of the flanges is denoted $h$ and the width of the flanges is denoted by $b$. The according expression employed to compute the position of the shear center is:

$$
Y_{C}=\frac{h^{2} \cdot b^{2} \cdot \delta}{4 \cdot I_{Y}}
$$


In the next section we will survey the way how the shear center twisting effect may be modeled using the finite element method.

\section{FINITE ELEMENT MODELS}

The section presented in figure 1 was defined using the Femap/NASTRAN software, using the beam element type.

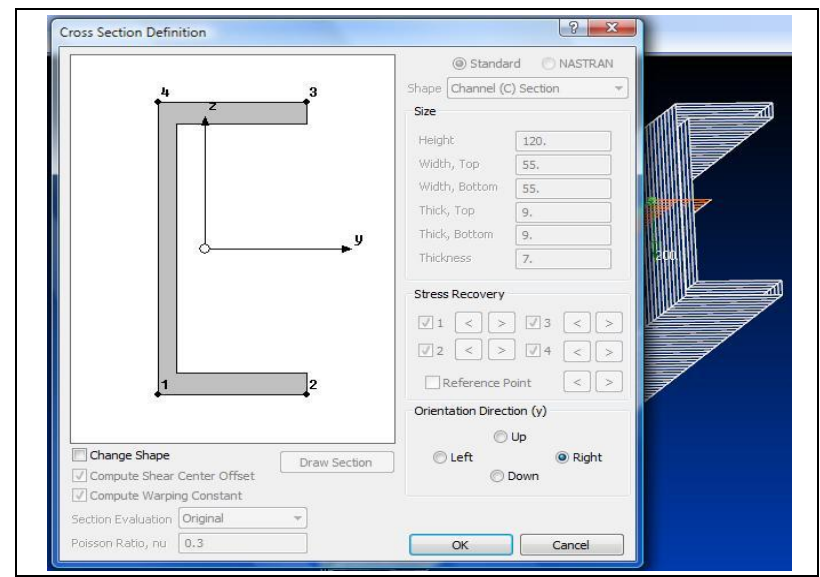

Fig. 1. Model of a C-shape beam

As it can be noticed, for each dimension of each rectangle, values can be easily assigned.Moreover, the user is allowed to select either 'standard' or 'NASTRAN' element types.

Figure 2 presents the results of the numerical model which uses beam-type elements.

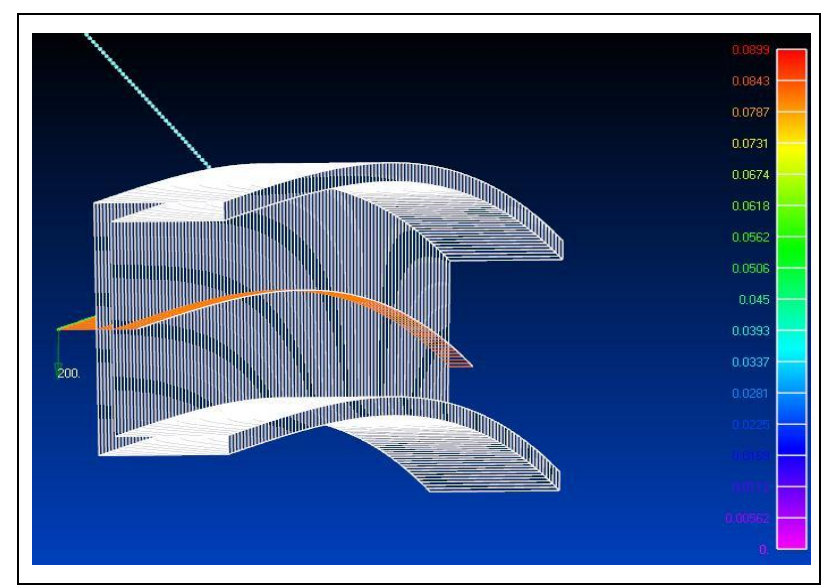

Fig. 2. Results of the finite element model which uses a beam element

As it can be noticed, there is no rotation of the section, so the model does not take into consideration the shear center effect. This is explained by the beamelement theory which considers only the effects of the bending, without shear effects.

The same loads are considered using Hex and Tet elements and the results are in the figure above.

The next study is done using the NX software application, which belongs to the same 'family' of software for engineering designed by Siemens, which also includes Femap/NASTRAN.

The figure below presents the definition of the beam geometry in NX and the results of the finite element model which uses Tet elements.

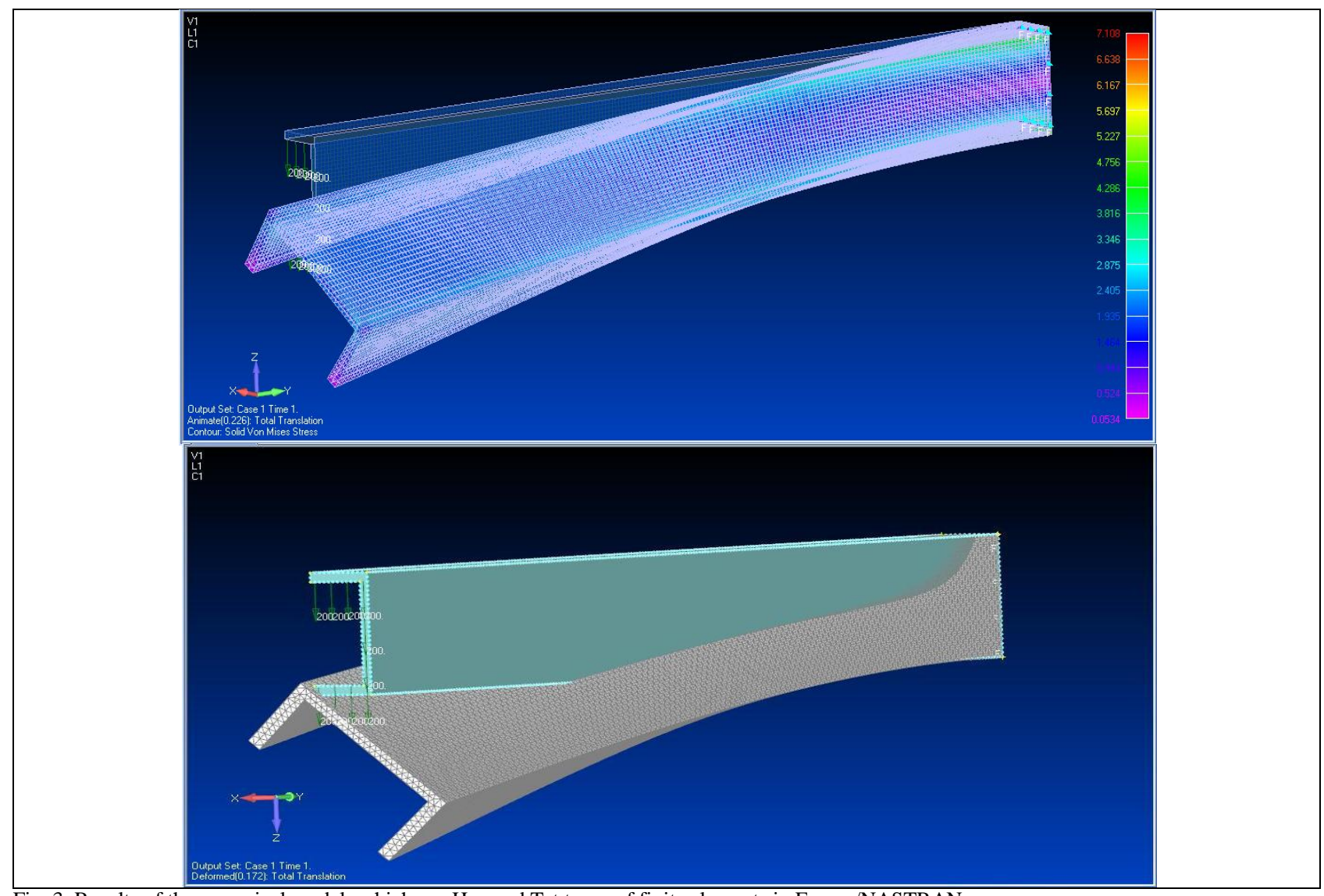

Fig. 3. Results of the numerical models which use Hex and Tet types of finite elements in Femap/NASTRAN 


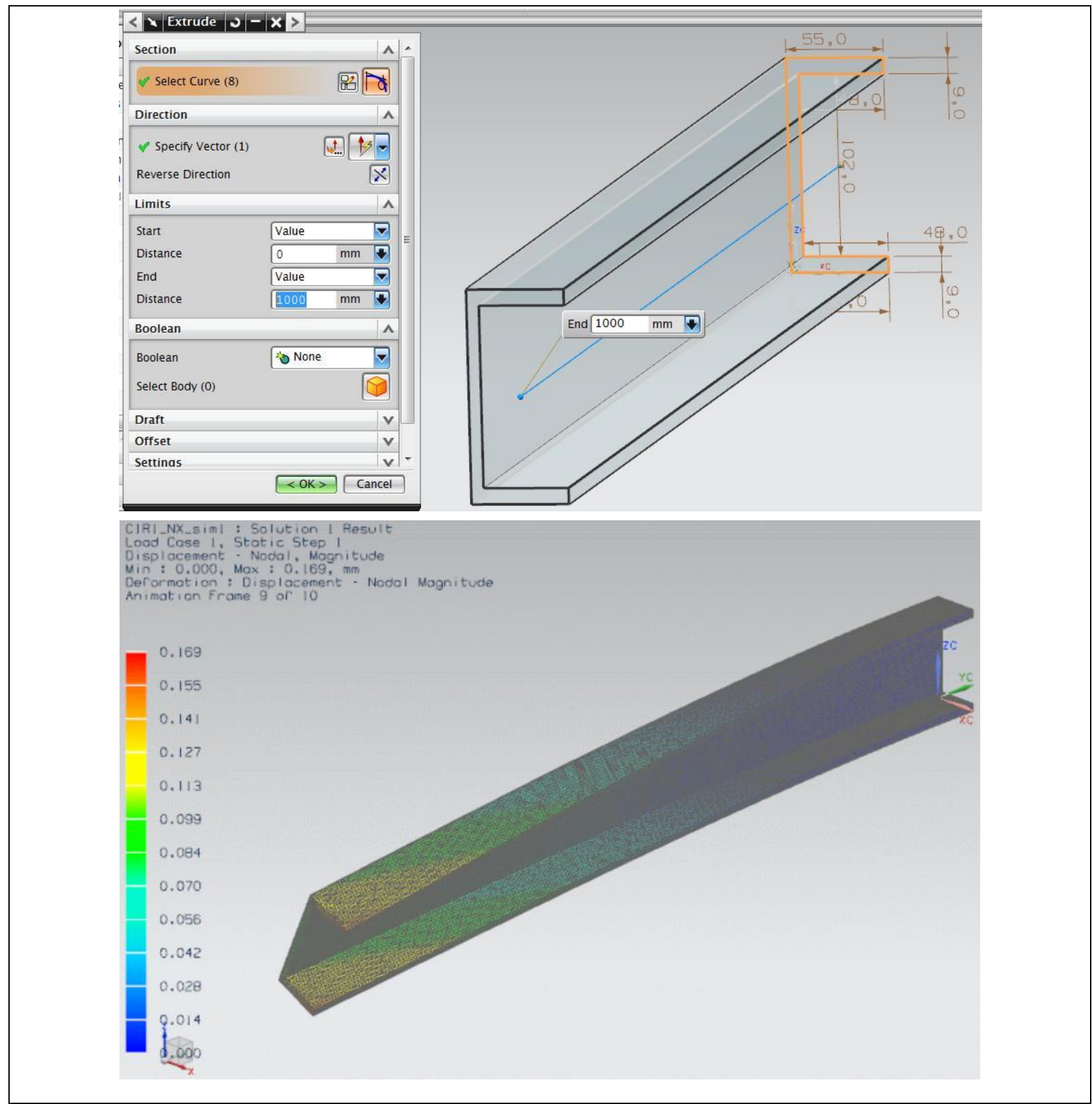

Fig. 4. Definition of the beam geometry in NX and results of the finite element model

As it can be noticed from the several finite element models above, the results of the numerical model must be in accord with the real behavior of the structure to be studied.

The first model which uses beam-type elements does not take into consideration the effect of the tangential stresses in the upper and lower flanges of the C-shape section. This is why the results present only the deflection of the cantilever, which is appropriate for pure bending only.

For large structures it is inappropriate to model the beams using solid elements (Tet or Hex), so there may be used other options.

First idea is to use beams with symmetrical crosssection, which can be chosen from the catalogues of preengineered members. The second option is to neglect the effect of the tangential stresses for short beams which are not used under large loads. The third option is to use a self-compensation effect, by positioning in a symmetrical way the members in the overall cross-section of the beam. The two members of the section must be connected one to the other at equal distances with additional elements which are located at a certain short distance one to the other. An additional condition is to equally load the two components of the beam. An example is given in figure 5.

\section{CONCLUSION}

Computer aided engineering software applications are powerful instruments of design and analysis in mechanical and structural engineering.

Regarding the limitations of a research study, several effects may be taken into account, such as influence of 


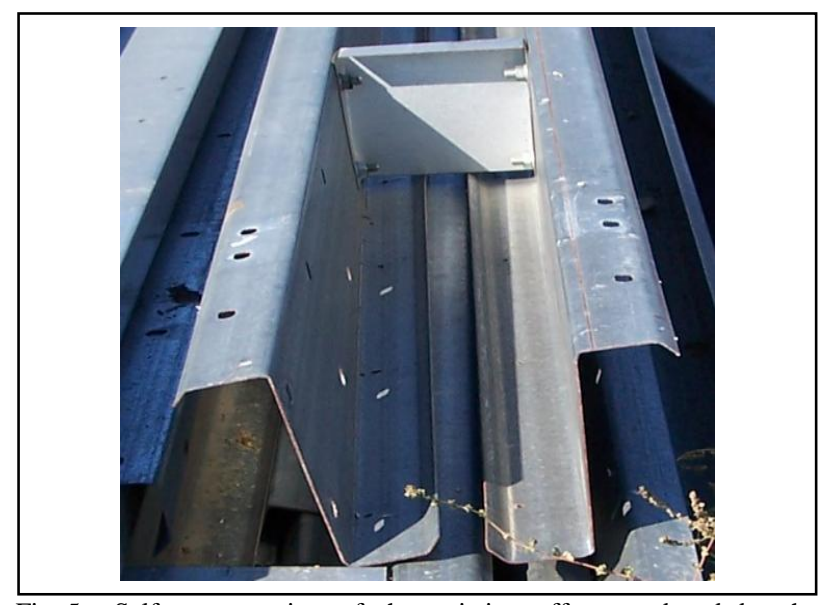

Fig. 5. Self-compensation of the twisting effect produced by the tangential stresses

the heat transfer onto a given mechanical structure or the interaction between a fluid and a structure in order to have accurate results of the investigation of a complex phenomenon.

Our case-study presents the effect of the tangential stresses and bending which create a rotation of the crosssection with respect to a shear center. The phenomenon is produced by the tangential stresses, so an element which considers the stresses should be used for the analysis, such as the solid elements (Tet and Hex).These examples are relevant for educational purposes, [6], [7] in order to emphasize on the importance of the theoretical aspects.

There are two directions regarding the future research plans. The theoretical study will be continued with the development of an algorithm and computer code for the automatic calculus of the location of the shear center.The experimental study will measure the stresses and the deflection of a U-beam bar the angle of rotation of the free end of the cantilever. Both studies will be employed in more complex research projects.

If large structures must be analyzed, the local effects might not be considered relevant by the numerical analyst, which can produce structure failure.

In these cases, the use of the practical solutions such as the self-compensating effects or considerations resulted from experience and practice isa valuable source of know-how.

Finally we must remind that the theoretical background of the phenomena to be studied and of the modern instruments extensively used nowadays, are paramount for a safe and economic design.

\section{ACKNOWLEDGEMENTS}

Several of the ideas presented in the paper are the result of the models developed in the framework of the scientific research study 'Development of computer assisted marine structures', Emil Oanta, Cornel Panait, Ghiorghe Batrinca, Alexandru Pescaru, Alexandra Nita, Feiza Memet, which is a component of the RoNoMar project, 2010, sponsor of this paper.
Ideas regarding the computer based instruments in applied elasticity are the result of the models developed in the framework of the MIEC2010 bilateral Ro-Md research project, Oanta, E., Panait, C., Lepadatu, L., Tamas, R., Constantinescu, M., Odagescu, I., Tamas, I., Batrinca, G., Nistor, C., Marina, V., Iliadi, G., Sontea, V., Marina, V., Balan, V. (2010-2012), "Mathematical Models for Inter-Domain Approaches with Applications in Engineering and Economy", MIEC2010 - Bilateral Romania-Moldavia Scientific Research Project, under the supervision of the National Authority for Scientific Research (ANCS), Romania, that is the follow-up of the ID1223 scientific research project: Oanta, E., Panait, C., Nicolescu, B., Dinu, S., Pescaru, A., Nita, A., Gavrila, G., (2007-2010), "Computer Aided Advanced Studies in Applied Elasticity from an Interdisciplinary Perspective", under the supervision of the National University Research Council (CNCSIS), Romania.

\section{REFERENCES}

[1] Barber, J. R.; (2011), Intermediate Mechanics of materials, 2nd Edition, Springer, 618 p., ISSN 0925-0042, ISBN 978-94-0070294-3, e-ISBN 978-94-007-0295-0, DOI 10.1007/978-94-0070295-0, Springer Dordrecht Heidelberg London New York

[2] Oanta, E.; Barhalescu, M. \& Sabau, A., (2011). Management of Change Based on Creative Inter-Domain Syntheses, Proceedings of the $7^{\text {th }}$ International Conference on Management of Technological Changes, September $1^{\text {st }}-3^{\text {rd }}, \quad 2011$, Alexandroupolis, Greece, Vol II, ISBN (Vol. II) 978-960-994863-0, ISBN 978-960-99486-1-6, Costache Rusu (Ed.), pp. 589-592, Democritus University of Thrace, Alexandroupolis, Greece, 2011

[3] Oanta, E.; Panait, C.; Batrinca, G. \& Pescaru, A., (2011). Basic Concepts to Design the Software Application of a Computer Based Mechanical Engineering Model, Annals of DAAAM for 2011 \& Proceedings of the $22^{\text {nd }}$ International DAAAM Symposium, ISBN 978-3-901509-83-4, ISSN 1726-9679, pp 0505-0506, Branko Katalinic (Ed.), Published by DAAAM International, Vienna, Austria 2011

[4] Oanta, E.; Panait, C.; Batrinca, G. \& Pescaru, A., (2011). Computer Based Educational Model of the Bent Hull in the Context of the Maritime Education, Annals of DAAAM for 2011 \& Proceedings of the $22^{\text {nd }}$ International DAAAM Symposium, ISBN 978-3-901509-83-4, ISSN 1726-9679, pp 0503-0504, Branko Katalinic (Ed.), Published by DAAAM International, Vienna, Austria 2011

[5] Oanta, E.; Panait, C.; Marina, V.; Marina, V.; Lepadatu, L.; Constantinescu, E.; Barhalescu, M. L.; Sabau, A. \& Dumitrache, C. L., (2011). Mathematical Composite Models, a Path to Solve Research Complex Problems, Annals of DAAAM for 2011 \& Proceedings of the $22^{\text {nd }}$ International DAAAM Symposium, ISBN 978-3-901509-83-4, ISSN 1726-9679, pp 0501-0502, Branko Katalinic (Ed.), Published by DAAAM International, Vienna, Austria 2011

[6] Sabau, A.; Oanta, E. \& Barhalescu, M., (2011). Impact Of The Use Of The Modern Methods In The Training Of Marine Engineer Cadets,Proceedings of the $7^{\text {th }}$ International Conference on Management of Technological Changes, September $1^{\text {st }}-3^{\text {rd }}$, 2011, Alexandroupolis, Greece, Vol II, ISBN (Vol. II) 978-96099486-3-0, ISBN 978-960-99486-1-6, Costache Rusu (Ed.), pp. 421-424, Democritus University of Thrace, Alexandroupolis, Greece, 2011

[7] Sabau, A.; Barhalescu, M. \& Oanta, E., (2011). Simulation Programs in Teaching Activity, Proceedings of the $7^{\text {th }}$ International Conference on Management of Technological Changes, September $1^{\text {st }}-3^{\text {rd }}, 2011$, Alexandroupolis, Greece, Vol II, ISBN (Vol. II) 978-960-99486-3-0, ISBN 978-960-99486-1-6, Costache Rusu (Ed.), pp. 425-428, Democritus University of Thrace, Alexandroupolis, Greece, 2011 